\title{
Topographic and vegetation effects on snow accumulation in the southern Sierra Nevada: a statistical summary from lidar data
}

\author{
Z. Zheng ${ }^{1}$, P. B. Kirchner ${ }^{2,3}$, and R. C. Bales ${ }^{1,4}$ \\ ${ }^{1}$ Department of Civil and Environmental Engineering, UC Berkeley, Berkeley, CA, USA \\ ${ }^{2}$ Joint Institute for Regional Earth System Science and Engineering, Pasadena, CA, USA \\ ${ }^{3}$ Southwest Alaska Network, National Park Service, Anchorage, AK, USA \\ ${ }^{4}$ Sierra Nevada Research Institute, UC Merced, Merced, CA, USA \\ Correspondence to: Z. Zheng (zeshi.z@berkeley.edu)
}

Received: 20 July 2015 - Published in The Cryosphere Discuss.: 19 August 2015

Revised: 12 January 2016 - Accepted: 13 January 2016 - Published: 28 January 2016

\begin{abstract}
Airborne light detection and ranging (lidar) measurements carried out in the southern Sierra Nevada in 2010 in the snow-free and peak-snow-accumulation periods were analyzed for topographic and vegetation effects on snow accumulation. Point-cloud data were processed from four primarily mixed-conifer forest sites covering the main snow-accumulation zone, with a total surveyed area of over $106 \mathrm{~km}^{2}$. The percentage of pixels with at least one snowdepth measurement was observed to increase from 65-90 to $99 \%$ as the sampling resolution of the lidar point cloud was increased from 1 to $5 \mathrm{~m}$. However, a coarser resolution risks undersampling the under-canopy snow relative to snow in open areas and was estimated to result in at least a $10 \mathrm{~cm}$ overestimate of snow depth over the main snowaccumulation region between 2000 and $3000 \mathrm{~m}$, where $28 \%$ of the area had no measurements. Analysis of the $1 \mathrm{~m}$ gridded data showed consistent patterns across the four sites, dominated by orographic effects on precipitation. Elevation explained $43 \%$ of snow-depth variability, with slope, aspect and canopy penetration fraction explaining another $14 \%$ over the elevation range of $1500-3300 \mathrm{~m}$. The relative importance of the four variables varied with elevation and canopy cover, but all were statistically significant over the area studied. The difference between mean snow depth in open versus under-canopy areas increased with elevation in the rain-snow transition zone (1500-1800 m) and was about $35 \pm 10 \mathrm{~cm}$ above $1800 \mathrm{~m}$. Lidar has the potential to transform estimation of snow depth across mountain basins, and including local canopy effects is both feasible and important for accurate assessments.
\end{abstract}

\section{Introduction}

In the western United States, ecosystem processes and water supplies for agricultural and urban users depend on the mountain snowpack as the primary source of late-spring and early-summer streamflow (Bales et al., 2006). Knowledge of spring snowpack conditions within a watershed is essential if water availability and flood peaks following the onset of melt are to be accurately predicted (Hopkinson et al., 2001). California's multi-billion-dollar agricultural economy as well as multi-trillion-dollar urban economy depend on these predictions (California Department of Water Resources, 2013). Both topographic and vegetation factors are important in influencing the snowpack conditions, as they closely interact with meteorological conditions to affect precipitation and snow distribution in the mountains (McMillen, 1988; Raupach, 1991; Wigmosta et al., 1994). However, mountain precipitation is poorly understood at multiple spatial scales because it is governed by processes that are neither well measured nor accurately predicted (Kirchner et al., 2014). Snow accumulation across the mountains is primarily influenced by orographic processes, involving feedbacks between atmospheric circulation and terrain (Roe, 2005; Roe and Baker, 2006). In most forested regions, snow distribution is highly sensitive to vegetation structure (Anderson, 1963; Revuelto et al., 2015; Musselman et al., 2008), and canopy interception, sublimation and unloading result in less accumulation of snow beneath the forest canopies in comparison with canopy gaps (Berris and Harr, 1987; Golding and Swanson, 1986; Mahat and Tarboton, 2013; Sturm, 1992). 
The Sierra Nevada serves as a barrier to moisture moving inland from the Pacific, has an ideal orientation for producing orographic precipitation, and thus exerts a strong influence on the upslope amplification of precipitation (Colle, 2004; Rotach and Zardi, 2007; Smith and Barstad, 2004). Recent studies provide insight on how orographic and topographic factors affect snow depth in the Alps (Grünewald et al., 2013, 2014; Lehning et al., 2011), suggesting that similar studies could be extended to the Sierra Nevada. And among the forested regions of the mountains, the mixed-conifer and subalpine zones cover most of the high-elevation, seasonally snow-covered area.

In situ, operational measurements of snow water equivalent (SWE) in the Sierra Nevada come from monthly manual snow surveys and daily snow-pillow observations (Rosenberg et al., 2011). Meteorological stations and remotesensing products also provide estimates of precipitation and snow accumulation (Guan et al., 2013). Cost, data coverage, accuracy (Julander et al., 1998) and basin-scale representativeness are issues for in situ monitoring of SWE in mountainous terrain (Rice and Bales, 2010). Satellite-based remote sensing, such as MODIS, has been used to map snow coverage in large or even global areas. However, it only provides snow-coverage information in open areas, and no direct information on snow depths (Molotch and Margulis, 2008). The SNOw Data Assimilation System (SNODAS) integrates data from satellite and in situ measurements with weatherforecast and physically based snow models, providing gridded SWE and snow-depth estimates (Barrett, 2003). However, since SNODAS has not been broadly assessed (Clow et al., 2012), its potential for evaluating snow distribution in mountain areas remains uncertain. Also, owing to its $1 \mathrm{~km}$ spatial resolution, the snow depth that SNODAS provides is a mixed representation of both open and canopy-covered areas.

An orographic-lift effect is observable in most of the above data (Howat and Tulaczyk, 2005; Rice et al., 2011), and a binary-regression-tree model using topographic variables as predictors has also been used for estimating the snow depth in unmeasured areas (Erickson et al., 2005; Erxleben et al., 2002; Molotch et al., 2005). However, regression coefficients could not be estimated accurately for most of the explanatory variables, except for elevation, and the consistency of the orographic trend as well as the relative importance of these variables is still unknown owing to the lack of representative measurements across different slopes, aspects and canopy conditions. Also, the stability of the variance explained by the model needs to be tested with denser measurements.

In recent years, airborne lidar has been used for highspatial-resolution distance measurements (Hopkinson et al., 2004) and has become an important technique for acquiring topographic data with sub-meter resolution and accuracy (Marks and Bates, 2000). Therefore, lidar provides a potential tool to help understand spatially distributed snow depth across mountain regions. With multiple returns from a sin- gle laser pulse, lidar has also been used to construct vegetation structures as well as observe conditions under the canopy, which helps produce fine-resolution digital elevation models (DEMs), vegetation structures and snow-depth information. However, the snow depth under canopy can not always be measured because of the signal-intensity attenuation caused by canopy interception (Deems and Painter, 2006; Deems et al., 2006). A recent report applied a univariateregression model to the snow depth measured in open areas using lidar, with a high-resolution DEM used to accurately quantify the orographic-lift effect on the snow accumulation just prior to melt (Kirchner et al., 2014). From this analysis it could be expected that lidar data might also help explain additional sources of snow distribution variability in complex, forested terrain.

The objective of the work reported here is to improve our understanding of how topographic and vegetation attributes affect snow accumulation in mixed-conifer forests. Using lidar data from four headwater areas in the southern Sierra Nevada, we addressed the following three questions. First, in forested mountain terrain what percentage of pixels have ground returns and thus provide snow-depth measurements at $1 \mathrm{~m}$ and coarser sampling resolutions, and what potential error is introduced by undersampling of snow under dense canopies? Second, what new information about orographic effects on precipitation versus accumulation is provided by these lidar data? Third, what is the effect of slope, aspect and canopy penetration fraction on snow accumulation, relative to elevation, and are effects consistent across sites?

\section{Methods}

\subsection{Study areas}

Our study areas are located in the southern Sierra Nevada, approximately $80 \mathrm{~km}$ east of Fresno, California (Fig. 1). The four headwater-catchment research areas - Bull Creek, Shorthair Creek, Providence Creek and Wolverton Basin - were previously instrumented, including meteorological measurements, in order to have a better knowledge of the hydrologic processes in this region (Bales et al., 2011; Hunsaker et al., 2012; Kirchner et al., 2014). The sites were chosen as part of multi-disciplinary investigations at the Southern Sierra Critical Zone Observatory, and they are also the main instrumented sites in the observatory. Wolverton is approximately $64 \mathrm{~km}$ southeast of the other three sites (Fig. 1) and is located in Sequoia National Park. Both snow-on and snow-off airborne lidar were flown in 2010 (Table 1) over these sites. The elevation of the survey areas is from 1600 to $3500 \mathrm{~m}$ elevation. Vegetation density generally decreases in high-elevation subalpine forest, with Wolverton also having a large area above treeline (Goulden et al., 2012). The precipitation has historically been mostly snow in the cold and wet winters for elevations above $2000 \mathrm{~m}$, and a rain-snow 
Table 1. Lidar data collection information.

\begin{tabular}{lllll}
\hline & Bull & Shorthair & Providence & Wolverton \\
\hline Snow-off flight date & 15 August 2010 & 13 August 2010 & 5 August 2010 & 13-15 August 2010 \\
Snow-on flight date & 24 March 2010 & 23 March 2010 & 23 March 2010 & 21-22 March 2010 \\
Area, km ${ }^{2}$ & 22.3 & 6.8 & 18.4 & 58.9 \\
Mean elevation, m & 2264 & 2651 & 1850 & 2840 \\
Elevation range, m & $1925-2490$ & $2436-2754$ & $1373-2207$ & $1786-3523$ \\
Canopy cover, \% & 51 & 43 & 62 & 30 \\
\hline
\end{tabular}

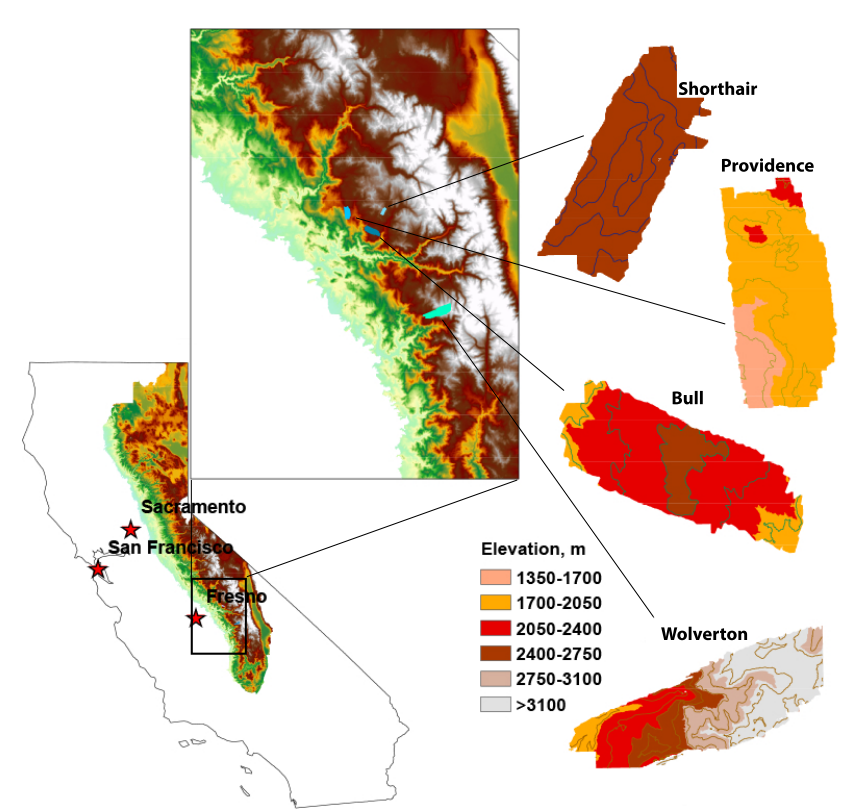

Figure 1. Study area and lidar footprints. Left: California with Sierra Nevada. Center: zoomed view to show the locations of lidar footprints. Right: elevation and $200 \mathrm{~m}$ contour map (100 m for Bull) of lidar footprints.

mix below $2000 \mathrm{~m}$, where most of Providence is located. The comparison between Providence and the other sites can help in assessing if observed trends are consistent above and below the rain-snow transition.

\subsection{Data collection}

All airborne lidar surveys were performed by the National Center for Airborne Laser Mapping (NCALM) using Optech GEMINI Airborne Laser Terrain Mapper. The scan angle and scan frequency were adjusted to ensure a uniform alongtrack and across-track point spacing (Table 2), with six GPS ground stations used for determining aircraft trajectory. The snow-on survey date was close to 1 April, which is used by operational agencies as the date of peak snow accumulation for the Sierra. Since the snow-on survey required four days to cover the four study areas, time-series in situ snow-depth data measured continuously from Judd Communications ul-
Table 2. Flight parameters and sensor settings.

\begin{tabular}{llll}
\hline \multicolumn{2}{c}{ Flight parameters } & \multicolumn{2}{c}{ Equipment settings } \\
\hline Flight altitude & $600 \mathrm{~m}$ & Wavelength & $1047 \mathrm{~nm}$ \\
Flight speed & $65 \mathrm{~m} \mathrm{~s}^{-1}$ & Beam divergence & $0.25 \mathrm{mrad}$ \\
Swath width & $233.26 \mathrm{~m}$ & Laser PRF & $100 \mathrm{kHz}$ \\
Swath overlap & $50 \%$ & Scan frequency & $55 \mathrm{~Hz}$ \\
Point density & $10.27 \mathrm{~m}^{-2}$ & Scan angle & $\pm 14^{\circ}$ \\
Cross-track resolution & $0.233 \mathrm{~m}$ & Scan cutoff & $3^{\circ}$ \\
Down-track resolution & $0.418 \mathrm{~m}$ & Scan offset & $0^{\circ}$ \\
\hline
\end{tabular}

trasonic depth sensors at Providence, Bull and Wolverton were used to estimate changes in snow depth during the survey period. While no snow accumulation was observed, snowpack densification and melting observed from the timeseries data were taken into considerations (Hunsaker et al., 2012; Kirchner et al., 2014). The snow-off survey was performed in August after snow had completely melted out in the study areas.

\subsection{Data processing}

Raw lidar data sets were pre-processed by NCALM and are available from the NSF OpenTopography website (http: //opentopography.org) in LAS format. The LAS point cloud, including both canopy and ground-surface points, are stored and classified as ground return and vegetation return. The $1 \mathrm{~m}$ resolution digital elevation models, generated from the lidar point-cloud data sets, were downloaded from the OpenTopography database and further processed in ArcMap 10.2 to generate $1 \mathrm{~m}$ resolution slope, aspect and northness raster products. Northness is an index for the potential amount of solar radiation reaching a slope on a scale of -1 to 1 , calculated from

$N=\sin (S) \times \cos (A)$,

where $N$ is the northness value; $S$ is the slope angle and $A$ is the aspect angle, both in degrees. For aspect angle $A$, north is either 0 or $360^{\circ}$. Northness is also the same as the aspect intensity (Kirchner et al., 2014) with $0^{\circ}$ focal aspect. Since in this analysis the snow-depth comparison is only discussed between north- and south-facing slopes, northness is used instead of aspect intensity for simplification. To construct the $1 \mathrm{~m}$ resolution canopy-height models from lidar data, the $1 \mathrm{~m}$ 


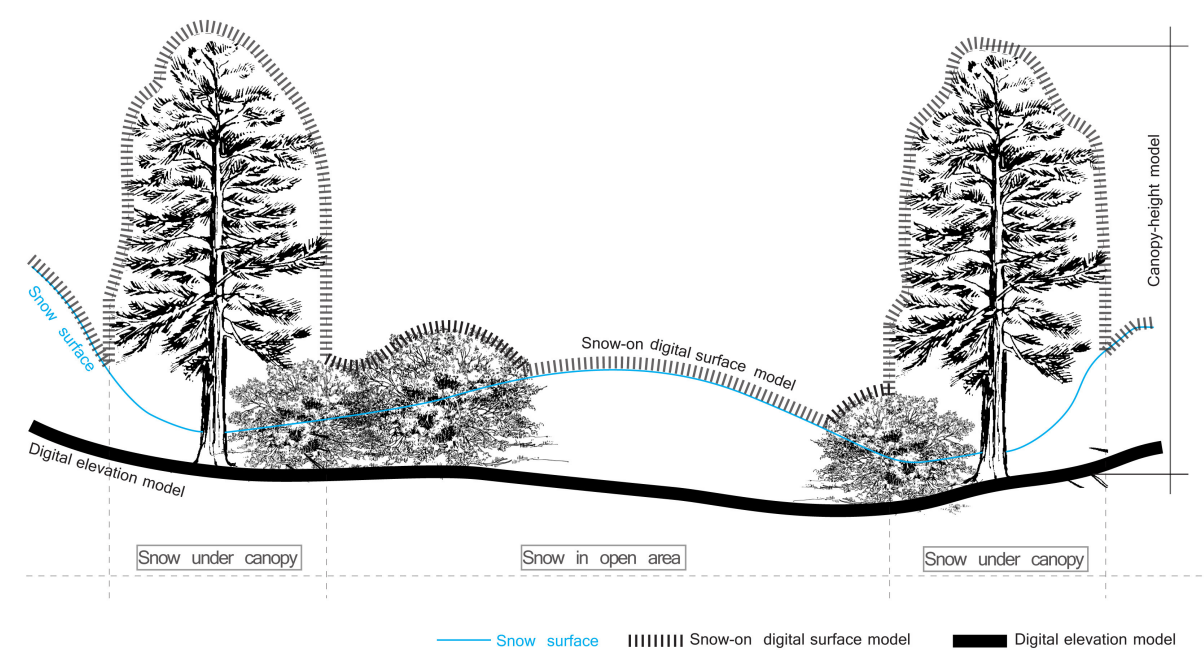

Figure 2. Subtracting the digital elevation model from the digital surface model will result in the canopy-height model. In this study the height of shrub vegetation is assumed smaller than $2 \mathrm{~m}$, while tree vegetation is taller than $2 \mathrm{~m}$.

digital elevation models were subtracted from the $1 \mathrm{~m}$ digital surface models that were rasterized from the first return of the laser pulses (Fig. 2).

The snow depths were calculated directly from the snowon lidar data. By referring to canopy-height models, all ground points in snow-on lidar data sets were classified as under canopy or in open areas. That is, if the ground point was coincident with canopy of $>2 \mathrm{~m}$ height, it was classified as under canopy, and otherwise in the open; i.e., a $2 \mathrm{~m}$ height was used to classify shrubs versus trees. In this study we assumed that shrubs did not affect the snow depth. After classification, snow depths were calculated by subtracting the values in the digital elevation model from the snow-on point-measurement values. The calculated point snow-depth data were further assigned into $1 \mathrm{~m}$ raster pixels, averaged within each pixel, formatted and then gap-filled by interpolation with pixel values around it. Since not all laser pulses that generated canopy-surface returns had ground returns (Fig. 3) and the ground-return percentage varied across the transition from the tree trunk to the edge of the canopy, interpolation was not applied to data under the canopy. The error rate of the calculated snow depth should be mainly from the instrumental elevation error, which is about $0.10 \mathrm{~m}$ (Kirchner et al., 2014; Nolan et al., 2015).

\subsection{Penetration fraction}

The open-canopy fraction is a factor that represents the forest density above a given pixel and is used to describe the influence of vegetation on snow accumulation and melt. However there is no algorithm to directly extract this information from lidar data. Here we use a novel approach that we call penetration fraction to approximate the open-canopy fraction from the lidar point cloud. With it we were able to quantify the impact of canopy on snow depth using linear regres-

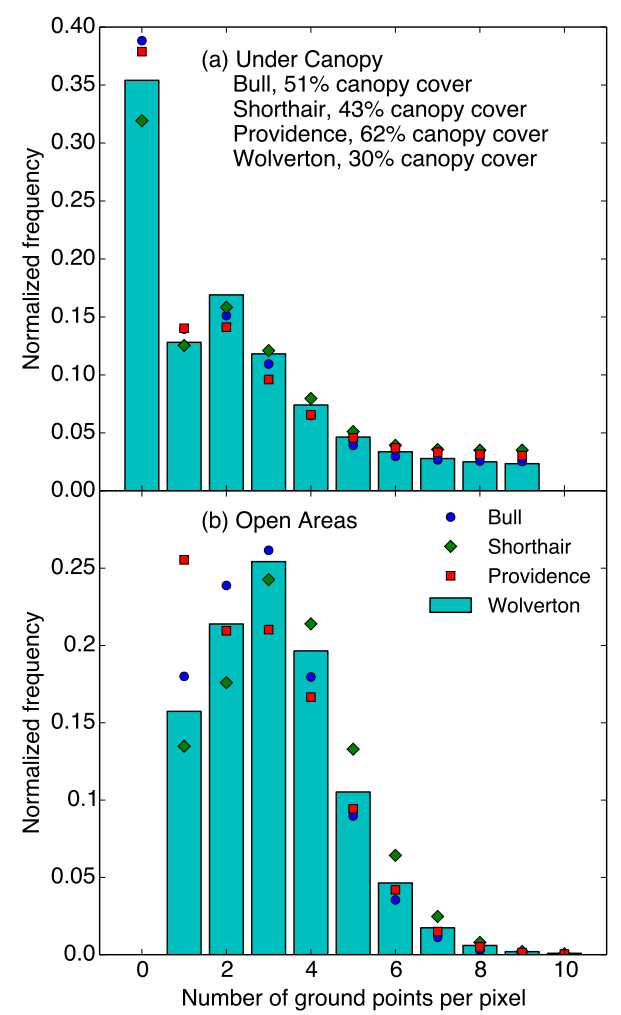

Figure 3. Normalized histogram of the number of ground points for (a) under-canopy and (b) open $1 \mathrm{~m}$ pixels.

sion. Penetration fraction is the ratio of the number of ground points to number of total points within each pixel (Fig. 4a). Whereas pixels are generally classified as under canopy or in the open (Kirchner et al., 2014), penetration fraction is an index of fraction open in a pixel. Because the electromagnetic radiation from both lidar and sunlight beams is intercepted 
(a)
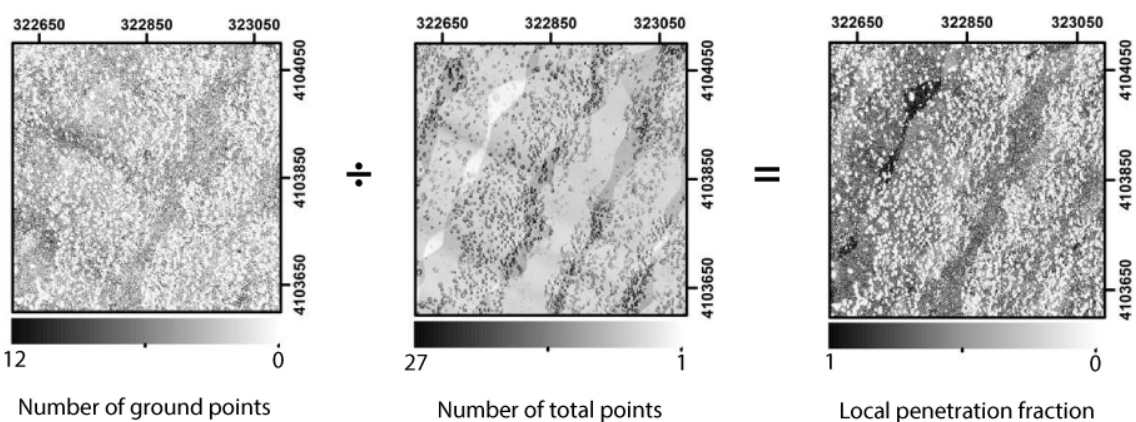

(b)

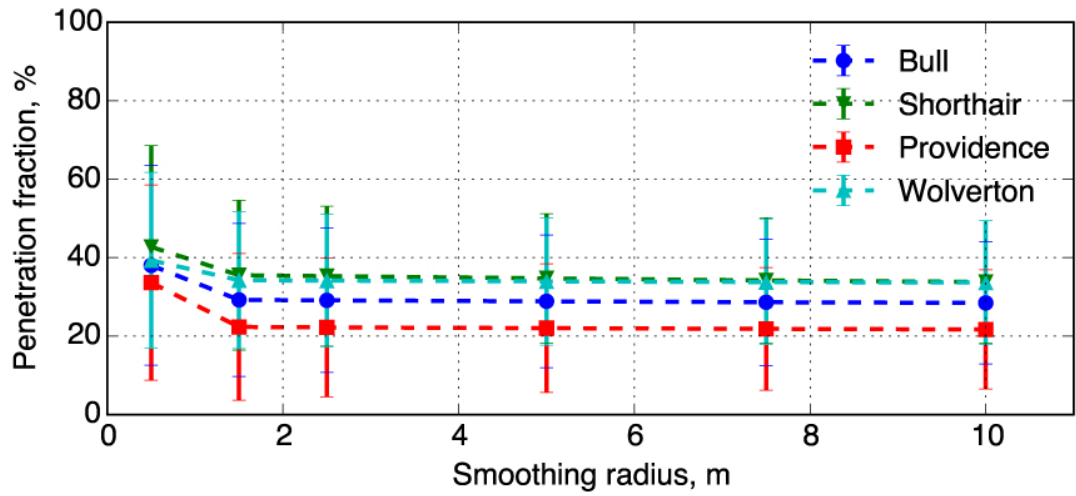

Figure 4. (a) Dividing the number of ground points of each $1 \mathrm{~m}$ pixel by the total number of points in the pixel gives the penetration fraction of the local pixel. (b) Sensitivity of the smoothed penetration fraction to the smoothing radius.

by canopies, the open-canopy fraction is used here as an index to represent the fraction of sunlight radiance received on the ground under vegetation. Therefore, penetration fraction of lidar is actually another form of estimating the opencanopy fraction (Musselman et al., 2013). However, undercanopy vegetation can also intercept the lidar beam, causing a bias. To eliminate this bias, the canopy-height model was used to check if the pixel was canopy covered by using the $2 \mathrm{~m}$ threshold value; if not, the local penetration fraction of the pixel was reset to 1 because the open-canopy fraction of a pixel could not be entirely represented by the penetration fraction. A spatial moving-average process was applied using a 2-D Gaussian filter to account for the effect of the vegetation around each pixel. Since the radius of the Gaussian filter needs to be specified by the user, we tested the sensitivity of smoothing results to the radius of the filter and found it is not sensitive when the radius is greater than $1.5 \mathrm{~m}$ (Fig. 4b). Therefore, we specified a radius of $5 \mathrm{~m}$ in the Gaussian filter.

\subsection{Statistical analysis}

The $1 \mathrm{~m}$ resolution snow-depth raster data sets were resampled into 2, 3, 4 and $5 \mathrm{~m}$ resolution. The percentage of pixels with snow-depth measurements was calculated by using the number of pixels with at least one ground return divided by the total number of pixels inside each site. The sensitivity of the percentage changes across different resampling resolutions and the consistency of the percentages across study sites at the same resampling resolution were analyzed by visualizing the percentages against sampling resolutions at all sites.

Using elevation, slope, aspect, penetration fraction and snow depth retrieved from lidar measurements, topographic and vegetation effects on snow accumulation were observed using residual analysis. Owing to orographic effects, there is increasing precipitation along an increasing elevation gradient in this area (Kirchner et al., 2014). Therefore, elevation was selected as the primary variable to fit the linearregression model for calculating the residual of snow depth. All snow-depth measurements from lidar were first separated as being either under canopy or in open areas, and then they were binned by elevation of the location where they were measured, with a bin size of $1 \mathrm{~m}$ elevation. As each elevation band had hundreds of snow-depth measurements after binning, the average of all snow depths was chosen as the representative snow depth, and the standard deviation calculated to represent the snow-depth variability within each elevation band. Coefficients of determination between snow depth and elevation of each site were calculated by linear regression. The fitted linear-regression model of each site was applied to 
Table 3. Linear-regression results, averaged snow depth vs. elevation at four sites.

\begin{tabular}{lcccc}
\hline & Bull & Shorthair & Providence & Wolverton \\
\hline$R^{2}$, open & 0.968 & 0.797 & 0.931 & 0.914 \\
$R^{2}$, vegetated & 0.978 & 0.737 & 0.921 & 0.972 \\
\hline Slope, open, cm per $100 \mathrm{~m}$ & 21.6 & 16.1 & 37.8 & 15.3 \\
Slope, vegetated, cm per $100 \mathrm{~m}$ & 19.9 & 13.1 & 26.0 & 13.4 \\
\hline
\end{tabular}

the DEM to estimate the snow depth. The residual of snow depth was calculated by subtracting the modeled snow depth from lidar-measured snow depth. The slope, aspect and penetration fraction were binned into $1^{\circ}$ slope, $1^{\circ}$ aspect and $1 \%$ penetration-fraction bins, with snow-depth residuals corresponding to each bin of every physiographic variable averaged and visualized along the variable gradient to check the existence of these physiographic effects.

For the variables found to correlate with the snow accumulation, the relative importance of each variable was calculated using the Random Forest algorithm (Breiman, 2001; Pedregosa et al., 2011). A multivariate linear-regression model was also applied to quantify the influence of the various physiographic variables on the snowpack distribution.

To calculate the snow-depth difference between open and canopy-covered areas along an elevation gradient, the $1 \mathrm{~m}$ resolution snow-depth data of the two conditions, open and canopy covered, were smoothed separately against elevation using locally weighted scatterplot smoothing (LOESS) (Cleveland, 1979). The snow-depth difference was then calculated by subtracting the smoothed canopy-covered snow depth from that in the open.

\section{Results}

The percentage of pixels having snow-depth measurements is sensitive to the sampling resolution used in processing the lidar point cloud to produce the raster data. Values go from about $65-90 \%$ across the four sites for $1 \mathrm{~m}$ resolution and gradually increase to $99 \%$ at $5 \mathrm{~m}$ resolution (Fig. 5). Note that the percentage increases in going from the lowerto higher-elevation sites, reflecting lower forest density at higher elevation.

The snow depths in open areas and under canopy show consistent increases with elevation across all sites (Fig. 6a and b). Although orographic effects may vary between individual storms across sites, these data suggest that the cumulative effect of the four main snowfall events prior to the lidar flight (Kirchner, 2013) resulted in similar patterns. The variability within an elevation band for open areas (Fig. 6c) is highest at about $1500 \mathrm{~m}$ and gradually decreases within the rain-snow transition up to $2000 \mathrm{~m}$ elevation. However, above $2000 \mathrm{~m}$ the pattern of variability with increasing elevation varies across sites. Note that values at the upper or lower

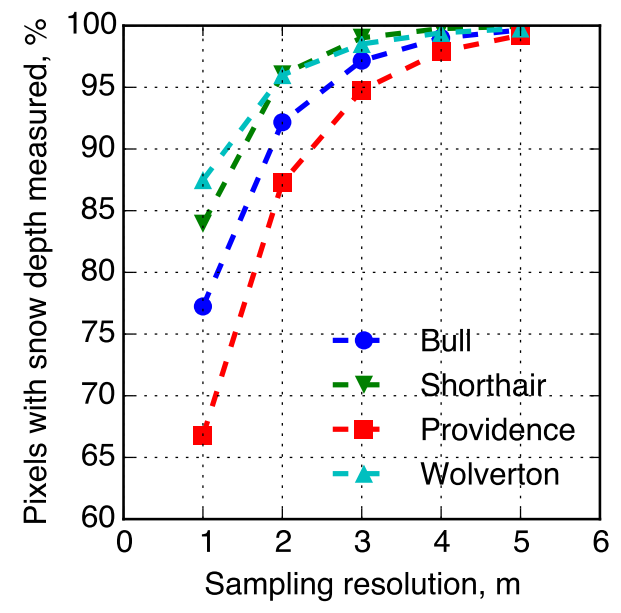

Figure 5. Sensitivity of the percent of pixels with snow depth measured to the sampling resolution used in processing the lidar point cloud at each site.

ends of elevation at each site have few pixels and thus may not have a representative distribution of other physiographic attributes (Fig. 6d). The forested area of all four sites combined spans the rain-snow transition zone in lower mixedconifer forest through snow-dominated subalpine forest, with significant areas above treeline higher up.

For each individual site, a least-squares linear regression of averaged snow depth versus elevation was used to investigate the spatial variability of snow depth (Table 3 ). The median elevation of the three sites increases from Providence to Bull to Shorthair. The lowest elevation at Providence Creek is less than $1400 \mathrm{~m}$, and snow depth increases steeply in this region at a rate of $38 \mathrm{~cm}$ per $100 \mathrm{~m}$ in open areas and $28 \mathrm{~cm}$ per $100 \mathrm{~m}$ under the canopy. Bull Creek has an elevation range of $2000-2400 \mathrm{~m}$, which is slightly higher than Providence, and has snow depth increasing at $21 \mathrm{~cm}$ per $100 \mathrm{~m}$ in open areas and $19 \mathrm{~cm}$ per $100 \mathrm{~m}$ under the canopy. For the Shorthair Creek site, which is the highest of the three, the snow depth increases at $17 \mathrm{~cm}$ per $100 \mathrm{~m}$ in open areas and $16 \mathrm{~cm}$ per $100 \mathrm{~m}$ under the canopy. Wolverton is $64 \mathrm{~km}$ further south and spans a wider elevation range, going from the rain-snow transition in mixed conifer, to subalpine forest, to some area above treeline. The average snow-depth increase is smallest among all four study sites, $15 \mathrm{~cm}$ per $100 \mathrm{~m}$ in open areas and $13 \mathrm{~cm}$ per $100 \mathrm{~m}$ under the canopy. Unlike the other three 


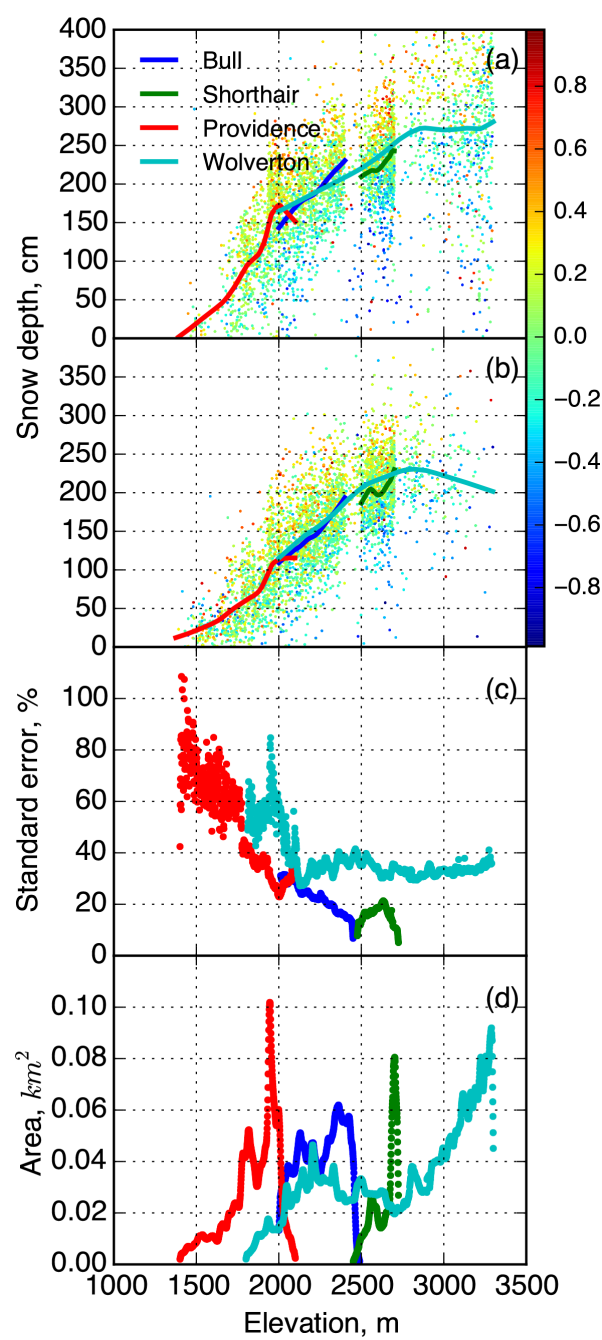

Figure 6. LOESS-smoothed snow depth with northness color-coded scatterplot of raw-pixel snow depth against elevation for (a) open and (b) under-canopy areas. (c) Standard error of the snow depth within each $1 \mathrm{~m}$ elevation band for open area. (d) Total area of each elevation band for both open and under-canopy areas. Values above $3300 \mathrm{~m}$ are not shown, where there are few data.

lower-elevation sites, the snow depth at Wolverton decreases above $3300 \mathrm{~m}$ elevation, and these high-elevation data were not included in the linear regression. The amount of area above this elevation is relatively small, and factors such as wind redistribution and the exhaustion of perceptible water can also affect snow depth at these elevations (Kirchner et al., 2014).

The residuals for snow in open areas were further analyzed for effects of slope, aspect and penetration fraction. The snow-depth residuals are negative and larger in magnitude on steeper slopes, i.e., less snow on steeper slopes (Fig. 7a). The residual also changes from positive to negative with aspect, reflecting deeper snow on north-facing versus south-facing slopes (Fig. 7b). The topographic effect can also be seen from the color pattern of northness observed in the scatterplots (Fig. 6a and b). The residual also changes from negative $20-40 \mathrm{~cm}$ to positive $20-40 \mathrm{~cm}$ as penetration fraction increases from 0 to $80 \%$, reflecting less snow under canopy (Fig. 7c). Considering all of these variables together, elevation is the most important variable at all sites except for Shorthair, which has a relatively small elevation range (Fig. 8). Aspect exerts a stronger influence than do slope and penetration fraction in open areas. However, for undercanopy areas, penetration is more dominant than aspect at two sites. The multivariate regression model was fitted to the data, with aspect transformed into a 0 to $180^{\circ}$ range (north to south). Fitted models can be represented as the following two equations for open area and under canopy, respectively:

$$
\begin{aligned}
\mathrm{SD} & =0.0011 \times \text { elevation }-0.0112 \times \text { slope } \\
& -0.0057 \times \text { aspect }+0.1802 \times \text { penetration, } \\
\mathrm{SD} & =0.0009 \times \text { elevation }-0.0128 \times \text { slope } \\
& -0.0046 \times \text { aspect }+0.9891 \times \text { penetration, }
\end{aligned}
$$

where SD is snow depth and $p$ values of all regression coefficients of the two models are all smaller than 0.01. The effects quantified in these two equations are mixtures of influences that affected both precipitation and post-deposition processes.

The snow-depth difference between open and canopycovered areas was calculated with elevation from locally smoothed snow depth. It generally increases from near zero at $1500 \mathrm{~m}$, where there is little snow but dense canopy, to $40 \mathrm{~cm}$ in the range of $1800-2000 \mathrm{~m}$, and it varies from near zero to $60 \mathrm{~cm}$ at higher elevations where snow is deeper and the canopy less dense (Fig. 9). It is apparent that the snowdepth difference increases with elevation in the rain-snow transition zone but lacks a clean pattern along either elevation gradient or penetration-fraction gradient when the elevation is higher.

\section{Discussion}

\subsection{Sensitivity of measurements to sampling resolution}

The results of analyzing the percentage of pixels with snow depth measured by lidar at different sampling resolutions illustrate that even high-density airborne lidar measurements do not have $100 \%$ coverage of the surveyed area at $1 \mathrm{~m}$ resolution, especially in densely forested areas. According to the snow-depth difference between snowpack in open areas and under canopy, a trade-off between accuracy and coverage happens when adjusting the resolution; lower sampling resolutions can introduce overestimation into the results. This is because, upon averaging, sub-pixel area under the canopy that was not measured may be represented by the open area that is measured, introducing an overestimation error into 


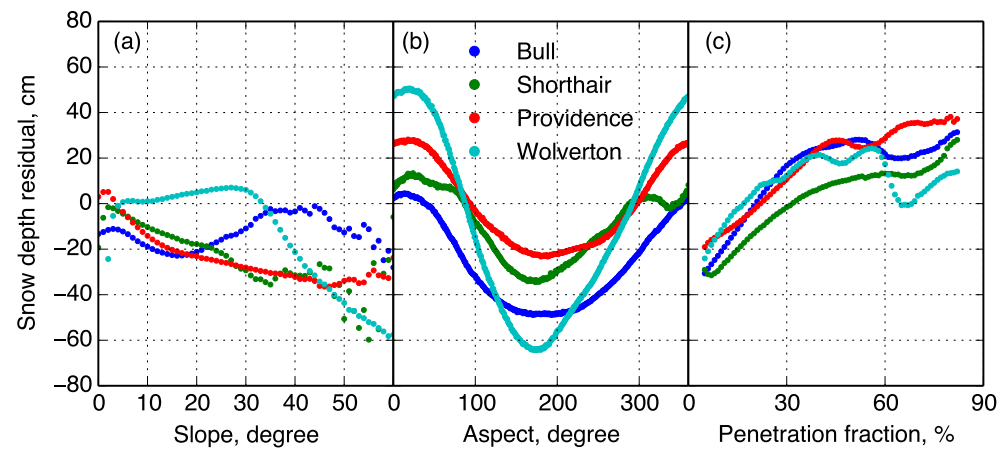

Figure 7. Average snow-depth residual, calculated as difference between lidar-measured snow depth and snow depth from the linearregression models (open areas), versus (a) slope, (b) aspect and (c) penetration fraction.

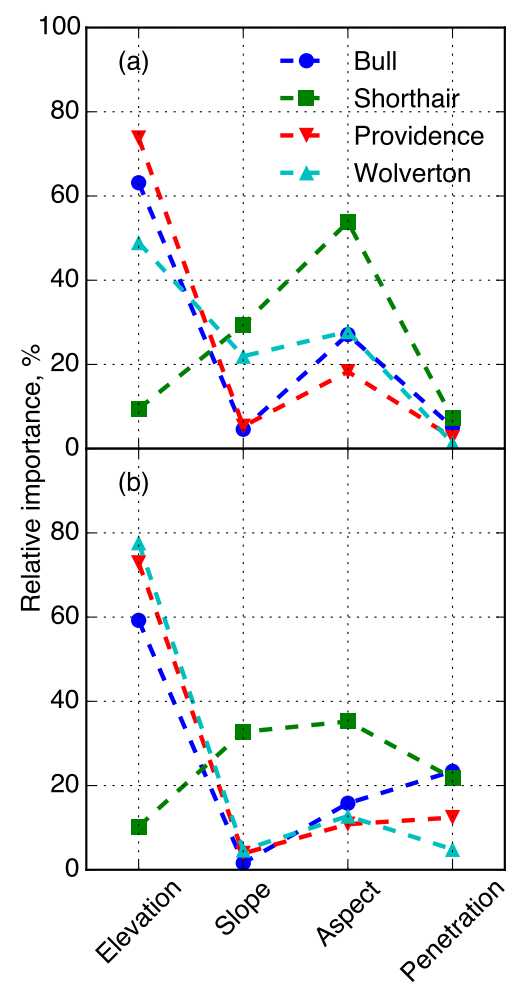

Figure 8. Relative importance of each physiographic variable in predicting the snow depth from each site for (a) open area and (b) under-canopy area.

the averaged snow depth of the pixel. In order to estimate that bias for each pixel, we would need more under-canopy snow-depth measurements at $1 \mathrm{~m}$ resolution. In our survey areas, $28 \%$ of the total area in the main snow-producing elevations of $2000-3000 \mathrm{~m}$ has no returns at $1 \mathrm{~m}$ resolution. Assuming that using open rather than under-canopy values would introduce a bias of at least $35 \mathrm{~cm}$ for these unmeasured areas, a $2 \mathrm{~m}$ mean snow depth will have about $10 \mathrm{~cm}$ or $5 \%$ overestimation over the whole area. The overestimation could be higher if the area with no returns represents

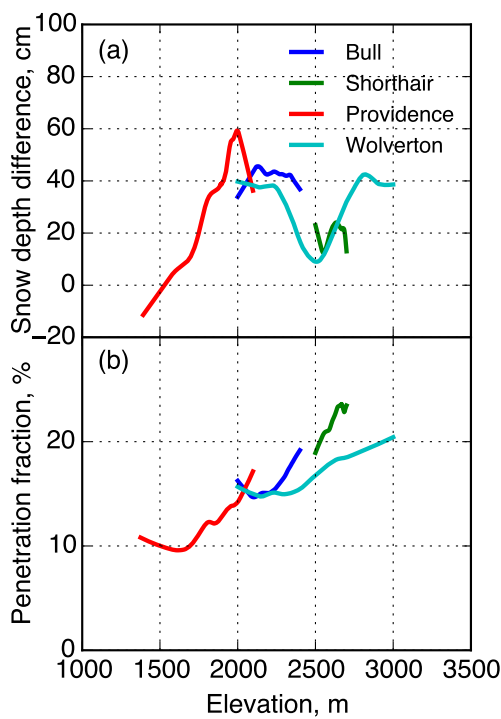

Figure 9. (a) Snow-depth difference along elevation for each site calculated from the LOESS-smoothed snow depth. (b) Average penetration fraction versus elevation for each site.

denser canopy with less snow than the under-canopy areas measured, and it could also be more significant for shallower snowpacks. It would also be higher for a less-dense point cloud, which would introduce uncertainty into both percentage canopy cover and open versus under-canopy snow-depth differences. Therefore, the sampling resolution for processing the lidar point cloud needs to be chosen according to the objective and accuracy tolerance of the study, and the average overestimation bias needs to be corrected for the study results.

\subsection{Physiographic effects on snow accumulation}

Below $3300 \mathrm{~m}$, the increasing trend of snow accumulation with elevation was observed for all sites (Fig. 6). Linear regression is applicable to model the relationship between snow depth and elevation when the study area has a broad 

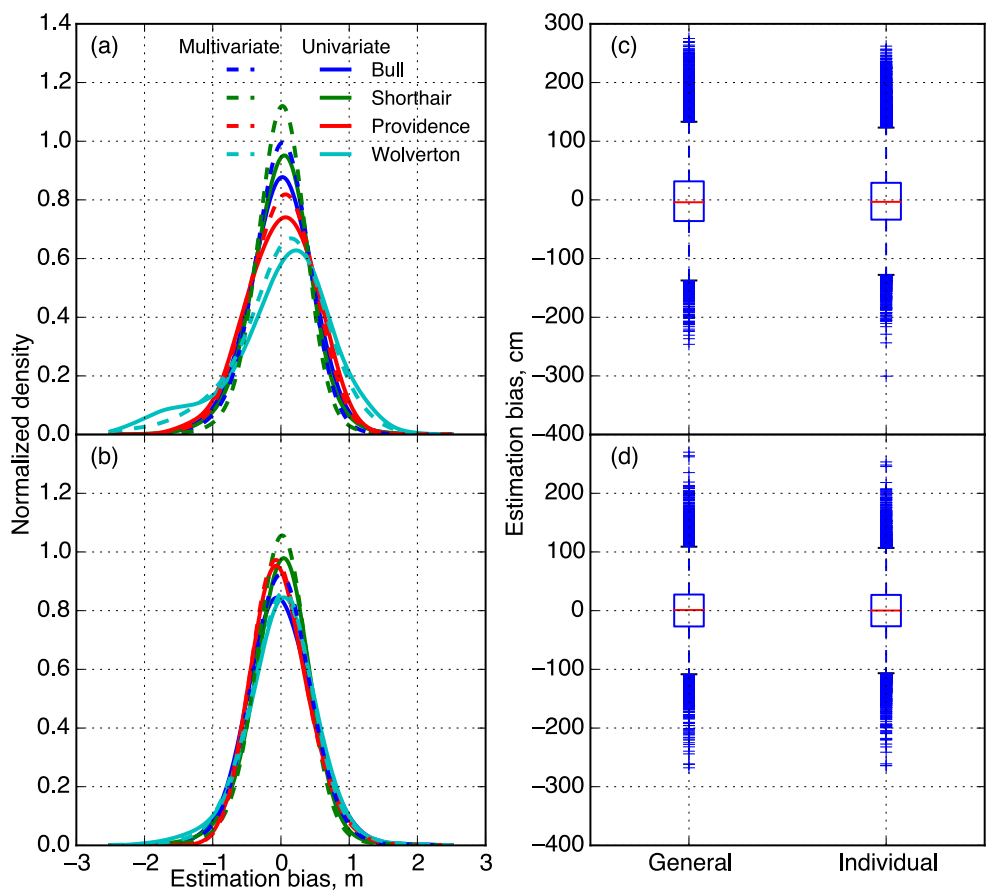

Figure 10. Normalized density of estimation bias for (a) open and (b) under-canopy areas. Estimation bias boxplots of using one general linear-regression model with all sites' data combined and four linear-regression models of each individual site for (c) and open (d) undercanopy areas.

Table 4. Coefficients of determination of univariate and multivariate linear-regression models.

\begin{tabular}{lcc}
\hline & $\begin{array}{c}\text { Univariate } \\
\text { model } \\
R^{2}\end{array}$ & $\begin{array}{c}\text { Multivariate } \\
\text { model } \\
R^{2}\end{array}$ \\
\hline Bull & 0.23 & 0.37 \\
Shorthair & 0.06 & 0.32 \\
Providence & 0.39 & 0.53 \\
Wolverton & 0.16 & 0.38 \\
All sites & 0.43 & 0.57 \\
\hline
\end{tabular}

elevation range. This holds true for all of our sites with the exception of Shorthair, where the elevation range is about $200 \mathrm{~m}$ and the coefficient of determination for this linearregression model is much smaller than for the other three sites, which have ranges greater than $500 \mathrm{~m}$. The bias of mean snow depth in the same elevation band between different sites is acceptable if the standard error is added to or subtracted from the mean (Fig. 6a-c). The data-collection time, spatial variation and variations of other topographic features can also introduce bias across sites. However, as data-collection time in this study only differed by a few days, in situ snow-depth sensor data suggest that the melting and densification effect was under $2 \mathrm{~cm}$ (https://czo.ucmerced. edu/dataCatalog_sierra.html). As for other topographic variables, the observation of a slope effect, shown as the trend lines in Fig. 7a and the negative regression coefficients of the two linear-regression models, could be explained by steeper slopes having higher avalanche potential, fewer trees and thus more wind; thus some snow is more likely to be lost from these slopes. Snowpack located in south-facing slopes receives higher solar radiation, with the snowmelt being accelerated (Kirchner et al., 2014). This explains the trends observed in Fig. $7 \mathrm{~b}$ and the negative regression coefficients of the multivariate models. Although lidar has measurement errors caused by slope and aspect (Baltsavias, 1999; Deems et al., 2013; Hodgson and Bresnahan, 2004), the error is not able to be quantitatively traced back to each variable, and we assumed that its influence on the trends could be neglected. As canopy interception results in reduced snow depth under canopy, the snow-depth residuals are found changing from negative to positive with penetration fraction and the regression coefficients are positive (Fig. 7c). The multivariate linear-regression model built from the lidar data is a significant improvement, as the variability of the snow distribution could explain 15-25\% more than the univariate linearregression model with elevation as the only predictive variable (Table 4) and the estimation bias has a narrower distribution (Fig. 10a and b). Also, fitting an individual linearregression model for each site is slightly better than using a general model with all data combined (Fig. 10c and d). This may be because an individual model can capture regional micro-climate within a site better than a general model. The opposite trend of the relative importance of predictive vari- 
ables observed in Shorthair is because it is a relatively flat site (Figs. 1 and 8), which implies that topographic variables other than elevation need to be considered when studying areas with small elevation ranges.

\subsection{Vegetation effects on snow distribution along elevation}

Under-canopy snow distribution is governed by multiple factors that affect the energy environment, as observed by melting (Essery et al., 2008; Gelfan et al., 2004) and accumulation rates (Pomeroy et al., 1998; Schmidt and Gluns, 1991; Teti, 2003). Our results show different responses when comparing the snow-depth difference between open and canopycovered areas between study sites (Fig. 9a). In the rain-snow transition zone from 1500 to $2000 \mathrm{~m}$ at Providence we see a sharp linear increase between open and under-canopy snow depth that is likely governed by the under-canopy energy environment and the canopy-interception effect on precipitation, which accelerate snowmelt and prevent accumulation of under-canopy snow. Above $2000 \mathrm{~m}$, the snow-depth difference observed at Bull and Shorthair stabilized around 40 and $20 \mathrm{~cm}$, respectively, with fluctuations less than $10 \mathrm{~cm}$ along elevation. Breaking from this pattern, the large dip in snow-depth difference, down to $10 \mathrm{~cm}$, observed at Wolverton at elevations of $2250-2750 \mathrm{~m}$ deviates from the $35-40 \mathrm{~cm}$ plateau. Also, the snow-depth difference at Shorthair stabilizes around $20 \mathrm{~cm}$, which is $20 \mathrm{~cm}$ lower than the stabilized value at Bull. Based on the scatterplots shown in Fig. 6a and b that are color-coded by northness, at an elevation range of 2300-2700 m, there are a lot more data points with both low snow depth and extremely negative northness in the open area than under the canopy, which implies that anisotropic distribution of other topographic variables is affecting the snow-depth difference. This is further shown by filtering out the data points not within a small certain range $(-0.1$ to 0.1$)$ of northness and then reproducing Fig. 9a using the filtered data. As presented in Fig. 11, it is apparent that the large dip at Wolverton is flattened out owing to a canopy effect of around $25-45 \mathrm{~cm}$. Thus a sigmoidal function was used to characterize the snow-depth difference changes with elevation, excluding topographic interactions. The interactions between topographic variables and vegetation are most likely attributable to the under-canopy snowpack being less sensitive to solar radiation versus snowpack in the open area (Courbaud et al., 2003; Dubayah, 1994; Essery et al., 2008; Musselman et al., 2008, 2012).

In spite of filtering the topographic effect, there is still about a $20 \mathrm{~cm}$ magnitude of fluctuation in the snow-depth difference, which might be attributed to various clearing sizes of open area at different locations and various vegetation types in forests (Hedstrom and Pomeroy, 1998; Pomeroy et al., 2002; Schmidt and Gluns, 1991); however, we were not able to explore these features of the sites from the current lidar data set.

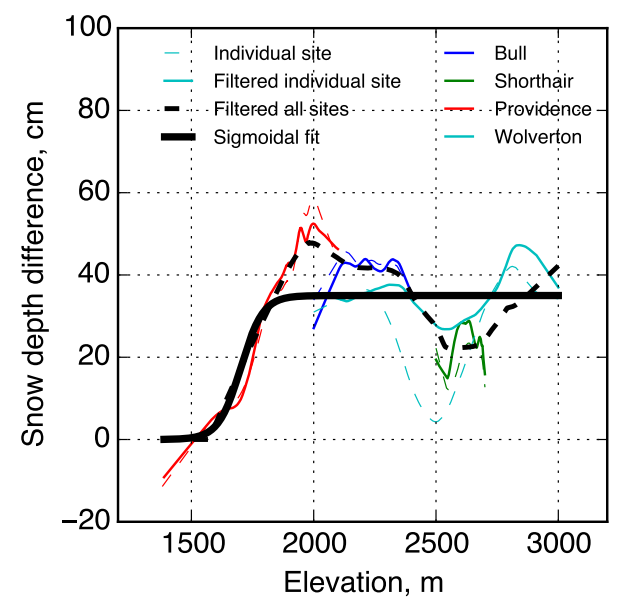

Figure 11. Snow-depth difference between open and under-canopy areas versus elevation, calculated as difference between raw $1 \mathrm{~m}$ pixel snow depth and northness-filtered $1 \mathrm{~m}$ pixel snow depth, together with the sigmoidal fit of the snow-depth difference.

\section{Conclusions}

The rasterized lidar data show that the percentage of pixels with at least one ground return, and thus a snow-depth measurement, increases from 65-90 to $99 \%$ as the sampling resolution increases from 1 to $5 \mathrm{~m}$. However, this coarser resolution may mask undersampling of under-canopy snow relative to snow in open areas. With about $28 \%$ of the area in dense mixed-conifer forest having no returns, using snow depths in open areas as estimates of snow depth under dense canopies would result in at least a $10 \mathrm{~cm}$ overestimation error in the average snow depth in the main snow-producing elevations of 2000-3000 m.

Using lidar data gridded at $1 \mathrm{~m}$ resolution, average snow depth within each $1 \mathrm{~m}$ elevation band shows a strong correlation with elevation and consistent pattern across all sites. The linear-regression models show that elevation explains $43 \%$ of snow-depth variability and that over $57 \%$ of the variability is explained when including all physiographic variables. This indicates that snow distribution in the southern Sierra Nevada is primarily influenced by an orographic-lift effect on precipitation. Snow-depth residuals calculated by de-trending the elevation dependency are correlated with slope, aspect and penetration fraction; the regression coefficients of these variables in the multivariate linear-regression model show that they are statistically significant in explaining the snow-depth variability, all with $p$ values smaller than 0.01 . Over the elevation range of $1500-3300 \mathrm{~m}$, snow depth decreases $1 \mathrm{~cm}$ per $1^{\circ}$ slope and decreases $0.5 \mathrm{~cm}$ per $1^{\circ}$ aspect in going from north to south. In open areas, snow depth increases $2 \mathrm{~cm}$ per $10 \%$ increase in penetration fraction, while under canopy the snow depth increases $10 \mathrm{~cm}$ per $10 \%$ penetration-fraction increase. Although the latter three variables were observed to 
be less important than elevation, the relative importance of all four variables varies with local elevation range and canopy.

The snow-depth difference between open and canopycovered areas increased in the rain-snow transition elevation range and then stabilized around $25-45 \mathrm{~cm}$ at high elevation. Fluctuations in certain elevation ranges are attributed partly to interactions from other topographic variables. Evidence of this is found by filtering northness into a narrow band, which results in these fluctuations flattening out.

Acknowledgements. This material is based on data and processing services provided by the OpenTopograhy Facility with support from the National Science Foundation under NSF Award Numbers 1226353 and 1225810. Research was supported by the National Science Foundation under NSF Award Numbers 1331939 and 1239521 and the UC Water Security and Sustainability Research Initiative funded by the University of California Office of the President (UCOP) (grant no. 13941). We are grateful to M. Sturm and A. Harpold for their thoughtful comments and reviews of this work. Also thank R. D. Brown, Q. Guo and N. P. Molotch for their helpful comments and J. Flanagan for providing canopy-height model data.

Edited by: R. Brown

\section{References}

Anderson, H. W.: Managing California's Snow Zone Lands for Water, USDA Forest Service Research Paper PSW-6, USDA Forest Service, 1963.

Bales, R. C., Molotch, N. P., Painter, T. H., Dettinger, M. D., Rice, R., and Dozier, J.: Mountain hydrology of the western United States, Water Resour. Res., 42, W08432, doi:10.1029/2005WR004387, 2006.

Bales, R. C., Hopmans, J. W., O'Geen, A. T., Meadows, M., Hartsough, P. C., Kirchner, P., Hunsaker, C. T., and Beaudette, D.: Soil Moisture Response to Snowmelt and Rainfall in a Sierra Nevada Mixed-Conifer Forest, Vadose Zone J., 10, 786-799, doi:10.2136/vzj2011.0001, 2011.

Baltsavias, E.: Airborne laser scanning: basic relations and formulas, ISPRS J. Photogramm. Remote Sens., 54, 199-214, doi:10.1016/S0924-2716(99)00015-5, 1999.

Barret, A. P.: National Operational Hydrologic Remote Sensing Center Snow Data Assimilation System (SNODAS) Products at NSIDC, NSIDC Special Report 11, National Snow and Ice Data Center, Boulder, CO, 2003.

Berris, S. N. and Harr, R. D.: Comparative snow accumulation and melt during rainfall in forested and clear-cut plots in the Western Cascades of Oregon, Water Resour. Res., 23, 135-142, doi:10.1029/WR023i001p00135, 1987.

Breiman, L.: Random forest, Mach. Learn., 45, 5-32, doi:10.1023/A:1010933404324, 2001.

California Department of Water Resources: California's Flood Future: Recommendations for Managing the State's Flood Risk, US Army Corps of Engineers, 2013.
Cleveland, W. S.: Robust Locally Weighted Regression and Smoothing Scatterplots, J. Am. Stat. Assoc., 74, 829-836, doi:10.2307/2286407, 1979.

Clow, D. W., Nanus, L., Verdin, K. L., and Schmidt, J.: Evaluation of SNODAS snow depth and snow water equivalent estimates for the Colorado Rocky Mountains, USA, Hydrol. Process., 26, 2583-2591, doi:10.1002/hyp.9385, 2012.

Colle, B. A.: Sensitivity of Orographic Precipitation to Changing Ambient Conditions and Terrain Geometries: An Idealized Modeling Perspective, J. Atmos. Sci., 61, 588-606, doi:10.1175/1520-0469(2004)061<0588:SOOPTC >2.0.CO;2, 2004.

Courbaud, B., De Coligny, F., and Cordonnier, T.: Simulating radiation distribution in a heterogeneous Norway spruce forest on a slope, Agr. Forest Meteorol., 116, 1-18, doi:10.1016/S01681923(02)00254-X, 2003.

Deems, J. S. and Painter, T. H.: Lidar measurement of snow depth: accuracy and error sources, Proc. 2006 Int. Snow Sci. Work. Telluride, Colorado, USA, Int. Snow Sci. Work., 330, 330-338, 2006.

Deems, J. S., Fassnacht, S. R., and Elder, K. J.: Fractal Distribution of Snow Depth from Lidar Data, J. Hydrometeorol., 7, 285-297, 2006.

Deems, J. S., Painter, T. H. and Finnegan, D. C.: Lidar measurement of snow depth: a review, J. Glaciol., 59, 467-479, doi:10.3189/2013JoG12J154, 2013.

Dubayah, R. C.: Modeling a solar radiation topoclimatology for the Rio Grande River Basin, J. Veg. Sci., 5, 627-640, doi:10.2307/3235879, 1994 .

Erickson, T. A., Williams, M. W., and Winstral, A.: Persistence of topographic controls on the spatial distribution of snow in rugged mountain terrain, Colorado, United States, Water Resour. Res., 41, 1-17, doi:10.1029/2003WR002973, 2005.

Erxleben, J., Elder, K., and Davis, R.: Comparison of spatial interpolation methods for estimating snow distribution in the Colorado Rocky Mountains, Hydrol. Process., 16, 3627-3649, doi:10.1002/hyp.1239, 2002.

Essery, R., Bunting, P., Rowlands, A., Rutter, N., Hardy, J., Melloh, R., Link, T., Marks, D. and Pomeroy, J.: Radiative Transfer Modeling of a Coniferous Canopy Characterized by Airborne Remote Sensing, J. Hydrometeorol., 9, 228-241, doi:10.1175/2007JHM870.1, 2008.

Gelfan, A. N., Pomeroy, J. W., and Kuchment, L. S.: Modeling Forest Cover Influences on Snow Accumulation, Sublimation, and Melt, J. Hydrometeorol., 5, 785-803, doi:10.1175/15257541(2004)005<0785:MFCIOS>2.0.CO;2, 2004.

Golding, D. L. and Swanson, R. H.: Snow distribution patterns in clearings and adjacent forest, Water Resour. Res., 22, 1931, doi:10.1029/WR022i013p01931, 1986.

Goulden, M. L., Anderson, R. G., Bales, R. C., Kelly, A. E., Meadows, M., and Winston, G. C.: Evapotranspiration along an elevation gradient in California's Sierra Nevada, J. Geophys. Res.Biogeo., 117, 1-13, doi:10.1029/2012JG002027, 2012.

Grünewald, T., Stötter, J., Pomeroy, J. W., Dadic, R., Moreno Baños, I., Marturià, J., Spross, M., Hopkinson, C., Burlando, P., and Lehning, M.: Statistical modelling of the snow depth distribution in open alpine terrain, Hydrol. Earth Syst. Sci., 17, 3005-3021, doi:10.5194/hess-17-3005-2013, 2013. 
Grünewald, T., Bühler, Y., and Lehning, M.: Elevation dependency of mountain snow depth, The Cryosphere, 8, 2381-2394, doi:10.5194/tc-8-2381-2014, 2014.

Guan, B., Molotch, N. P., Waliser, D. E., Jepsen, S. M., Painter, T. H., and Dozier, J.: Snow water equivalent in the Sierra Nevada: Blending snow sensor observations with snowmelt model simulations, Water Resour. Res., 49, 50295046, doi:10.1002/wrcr.20387, 2013.

Hedstrom, N. R. and Pomeroy, J. W.: Measurements and modelling of snow interception in the boreal forest, Hydrol. Process., 12, 1611-1625, doi:10.1002/(SICI)10991085(199808/09)12:10/11<1611::AID-HYP684>3.0.CO;2-4, 1998.

Hodgson, M. E. and Bresnahan, P.: Accuracy of Airborne LidarDerived Elevation: Empirical Assessment and Error Budget, Photogramm. Eng. Remote Sens., 70, 331-339, 2004.

Hopkinson, C., Sitar, M., Chasmer, L., Gynan, C., Agro, D., Enter, R., Foster, J., Heels, N., Hoffman, C., Nillson, J., and St Pierre, R.: Mapping the spatial distribution of snowpack depth beneath a variable forest canopy using airborne laser altimetry, Proc. 58th Annu. East. Snow Conf., Ottawa, Ontario, Canada, 2001.

Hopkinson, C., Sitar, M., Chasmer, L., and Treitz, P.: Mapping snowpack depth beneath forest canopies using airborne lidar, Photogramm. Eng. Remote Sens., 70, 323-330, 2004.

Howat, I. M. and Tulaczyk, S.: Trends in spring snowpack over a half-century of climate warming in California, USA, Ann. Glaciol., 40, 151-156, doi:10.3189/172756405781813816, 2005.

Hunsaker, C. T., Whitaker, T. W., and Bales, R. C.: Snowmelt Runoff and Water Yield Along Elevation and Temperature Gradients in California's Southern Sierra Nevada1, JAWRA J. Am. Water Resour. Assoc., 48, 667-678, doi:10.1111/j.17521688.2012.00641.x, 2012.

Julander, R. P., Wilson, G. R., and Nault, R.: The Franklin basin problem, 66th Annual Western Snow Conference, Snowbird, Utah, 1998.

Kirchner, P. B.: Dissertation for the degree of Doctor of Philosophy, University of California, Merced., 2013.

Kirchner, P. B., Bales, R. C., Molotch, N. P., Flanagan, J., and Guo, $\mathrm{Q}$.: LiDAR measurement of seasonal snow accumulation along an elevation gradient in the southern Sierra Nevada, California, Hydrol. Earth Syst. Sci., 18, 4261-4275, doi:10.5194/hess-184261-2014, 2014.

Lehning, M., Grünewald, T., and Schirmer, M.: Mountain snow distribution governed by an altitudinal gradient and terrain roughness, Geophys. Res. Lett., 38, 1-5, doi:10.1029/2011GL048927, 2011.

Mahat, V. and Tarboton, D. G.: Representation of canopy snow interception, unloading and melt in a parsimonious snowmelt model, Hydrol. Process., 28, 6320-6336, doi:10.1002/hyp.10116, 2013.

Marks, K. and Bates, P.: Integration of high-resolution topographic data with floodplain flow models, Hydrol. Process., 14, 2109-2122, doi:10.1002/10991085(20000815/30)14:11/12<2109::AID-HYP58>3.0.CO;2-1, 2000 .
McMillen, R. T.: An eddy correlation technique with extended applicability to non-simple terrain, Bound.-Lay. Meteorol., 43, 231-245, doi:10.1007/BF00128405, 1988.

Molotch, N. P. and Margulis, S. a.: Estimating the distribution of snow water equivalent using remotely sensed snow cover data and a spatially distributed snowmelt model: A multi-resolution, multi-sensor comparison, Adv. Water Resour., 31, 1503-1514, doi:10.1016/j.advwatres.2008.07.017, 2008.

Molotch, N. P., Colee, M. T., Bales, R. C., and Dozier, J.: Estimating the spatial distribution of snow water equivalent in an alpine basin using binary regression tree models: The impact of digital elevation data and independent variable selection, Hydrol. Process., 19, 1459-1479, doi:10.1002/hyp.5586, 2005.

Musselman, K. N., Molotch, N. P., and Brooks, P. D.: Effects of vegetation on snow accumulation and ablation in a midlatitude sub-alpine forest, Hydrol. Process., 22, 2767-2776, doi:10.1002/hyp.7050, 2008.

Musselman, K. N., Molotch, N. P., Margulis, S. A., Kirchner, P. B., and Bales, R. C.: Influence of canopy structure and direct beam solar irradiance on snowmelt rates in a mixed conifer forest, Agric. Forest Meteorol., 161, 46-56, doi:10.1016/j.agrformet.2012.03.011, 2012.

Musselman, K. N., Margulis, S. A., and Molotch, N. P.: Estimation of solar direct beam transmittance of conifer canopies from airborne LiDAR, Remote Sens. Environ., 136, 402-415, doi:10.1016/j.rse.2013.05.021, 2013.

Nolan, M., Larsen, C., and Sturm, M.: Mapping snow depth from manned aircraft on landscape scales at centimeter resolution using structure-from-motion photogrammetry, The Cryosphere, 9, 1445-1463, doi:10.5194/tc-9-1445-2015, 2015.

Pedregosa, F., Varoquaux, G., Gramfort, A., Michel, V., Thirion, B., Grisel, O., Blondel, M., Prettenhofer, P., Weiss, R., Dubourg, V., Vanderplas, J., Passos, A., Cournapeau, D., Brucher, M., Perrot, M., and Duchesnay, E.: Scikit-learn: Machine Learning in Python, J. Mach. Learn. Res., 12, 2825-2830, 2011

Pomeroy, J. W., Parviainen, J., Hedstrom, N., and Gray, D. M.: Coupled modelling of forest snow interception and sublimation, Hydrol. Process., 12, 2317-2337, doi:10.1002/(SICI)10991085(199812)12:15<2317::AID-HYP799>3.0.CO;2-X, 1998.

Pomeroy, J. W., Gray, D. M., Hedstrom, N. R., and Janowicz, J. R.: Prediction of seasonal snow accumulation in cold climate forests, Hydrol. Process., 16, 3543-3558, doi:10.1002/hyp.1228, 2002.

Raupach, M. R.: Vegetation-atmosphere interaction in homogeneous and heterogeneous terrain: some implications of mixed-layer dynamics, Vegetatio, 91, 105-120, doi:10.1007/BF00036051, 1991.

Revuelto, J., Lopez-Moreno, J. I., Azorin-Molina, C., and VicenteSerrano, S. M.: Canopy influence on snow depth distribution in a pine stand determined from terrestrial laser data, Water Resour. Res., 51, 3476-3489, doi:10.1002/2014WR016496, 2015.

Rice, R. and Bales, R. C.: Embedded-sensor network design for snow cover measurements around snow pillow and snow course sites in the Sierra Nevada of California, Water Resour. Res., 46, 1-13, doi:10.1029/2008WR007318, 2010.

Rice, R., Bales, R. C., Painter, T. H., and Dozier, J.: Snow water equivalent along elevation gradients in the Merced and Tuolumne River basins of the Sierra Nevada, Water Resour. Res., 47, W08515, doi:10.1029/2010WR009278, 2011. 
Roe, G. H.: Orographic Precipitation, Annu. Rev. Earth Planet. Sci., 33, 645-671, doi:10.1146/annurev.earth.33.092203.122541, 2005.

Roe, G. H. and Baker, M. B.: Microphysical and Geometrical Controls on the Pattern of Orographic Precipitation, J. Atmos. Sci., 63, 861-880, doi:10.1175/JAS3619.1, 2006.

Rosenberg, E. A., Wood, A. W., and Steinemann, A. C.: Statistical applications of physically based hydrologic models to seasonal streamflow forecasts, Water Resour. Res., 47, W00H14, doi:10.1029/2010WR010101, 2011.

Rotach, M. W. and Zardi, D.: On the boundary-layer structure over highly complex terrain: Key findings from MAP, Q. J. Roy. Meteorol. Soc., 133, 937-948, doi:10.1002/qj.71, 2007.
Schmidt, R. A. and Gluns, D. R.: Snowfall interception on branches of three conifer species, Can. J. Forest Res., 21, 1262-1269, doi:10.1139/x91-176, 1991.

Smith, R. B. and Barstad, I.: A Linear Theory of Orographic Precipitation, J. Atmos. Sci., 61, 1377-1391, doi:10.1175/15200469(2004)061<1377:ALTOOP>2.0.CO;2, 2004.

Sturm, M.: Snow distribution and heat flow in the taiga, Arctic, Antarct. Alp. Res., 24, 145-152, 1992.

Teti, P.: Relations between peak snow accumulation and canopy density, Forest Chron., 79, 307-312, 2003.

Wigmosta, M. S., Vail, L. W., and Lettenmaier, D. P.: A distributed hydrology-vegetation model for complex terrain, Water Resour. Res., 30, 1665-1680, doi:10.1029/94WR00436, 1994. 